\title{
Effectiveness of Health Education Program Regarding Foot Self-care on Risk for Developing Foot Ulcer Among Patients with Diabetes
}

\author{
Marwa Mosaad Ali", Samah Elsayed Ghonem \\ Medical-Surgical Nursing, Faculty of Nursing, Benha University, Benha, Egypt \\ Email address: \\ Medicine_s2000@yahoo.com (M. M. Ali) \\ ${ }^{*}$ Corresponding author
}

\section{To cite this article:}

Marwa Mosaad Ali, Samah Elsayed Ghonem. Effectiveness of Health Education Program Regarding Foot Self-care on Risk for Developing Foot Ulcer Among Patients with Diabetes. American Journal of Nursing Science. Vol. 8, No. 5, 2019, pp. $274-287$. doi: 10.11648/j.ajns.20190805.20

Received: August 15, 2019; Accepted: September 4, 2019; Published: September 29, 2019

\begin{abstract}
Background: Diabetic foot has been considered as a major health problem in adults, because of its high incidence in recent years. Self-care programs have a role in the early prevention of morbidity and mortality rate of the diabetic foot, promoting patients knowledge and self-care practices are a crucial need in this regard. Aim of the study: To evaluate the effectiveness of health education program regarding foot self-care on risk for developing foot ulcer among patients with diabetes Research design: A quasi-experimental research design was used to conduct the current study. Setting: The current study was conducted in diabetes unit and outpatient clinics, at Benha university hospital, during the period from the beginning of September 2018 to beginning of June 2019. Subjects: A purposive sample of 132 patients recruited according to the study formula based on the total number of patients who admitted to the study settings during 2017, were randomly assigned into 68 patients in control group and 64 patients in intervention group, using permuted randomization table. Tools of data collection: Four tools were utilized for data collection, Tool I- Structured interviewing questionnaire sheet, involved (part 3) Structured Knowledge questionnaire, Tool II- Self-care confidence scale, Tool III- Foot self-care behavior scale and Tool IV- Inlow's 60-second Diabetic Foot Screen. Results: Showed that mean score regarding knowledge, foot self-care confidence and behavior among intervention group were significantly higher after implementing intervention than among control group with a lower incidence of complications as well as there was a highly significant association between knowledge and self-efficacy among the studied groups, moreover the risk of developing foot ulcer was significantly lower among intervention group compared to control group post program implementation. Conclusion: The effectiveness of self-care educational program was approved in improving patients' knowledge, self-care confidence, behavior and in return lowering the risk of developing foot ulcer. Recommendation: Based on findings in this study, regular continuing self-care programs should be designed to enhance patients' ability to care for their foot with an emphasis on the most important risk factors and appropriate management in a large population.
\end{abstract}

Keywords: Diabetic Patients, Foot Self-care, Foot Ulcer, Health Education

\section{Introduction}

Diabetes is a chronic complex disease that requires continuous care, proper control as well as multifactorial strategies for reducing the risk of complications [4], also there is evidence from large randomized-controlled trials that good metabolic control in both type 1 and 2 diabetes can delay the onset and progression of these complications, which are divided into microvascular and macrovascular, one of the most prominent microvascular complications is neuropathy, related to the dysfunction of sensory, motor and autonomic neuropathy, which leading to impotence and diabetic foot disorders [31].

Diabetic foot disorder is considered one of the many different problems; the most clinically are ulceration, amputation and neuropathy. Many diabetic complications have a great impact on the foot and therefore no surprising that diabetic foot problems account for more hospitalization days 
than any other diabetic problems [9]. Regarding diabetic foot ulcers, it remains a serious medical problem, and is the most common complication of diabetes, which is extremely difficult to heal and exhibits a high recurrence rate. Thus, it is continuously receiving increased scientific attention, in an effort to improve outcomes [5].

Risk factors implicated in the development of diabetic foot ulcers are infection, older age, diabetic neuropathy, peripheral vascular disease, cigarette smoking, poor glycemic control, previous foot ulcerations or amputations, and ischemia of small and large blood vessels, also prior history of foot disease, foot deformities that produce abnormally high forces of pressure, renal failure, edema, as well as impaired ability to look after personal care [30].

Foot ulceration along with the associated physical restrictions, may negatively affect quality of life and further worsen depression [11], which can be prevented with Diabetes management, that requires major changes in behavior, which includes knowledge, skills and confidence to make improvements in self-care behavior and deal with associated psychological aspects, which in return prevent and delay potential complications as risk of foot ulceration [27].

Diabetes nurses have an effective role in prevention of foot ulcers and lower limb amputation by educational interventions, screening high risk people and providing health care, Nurses can teach patients how to perform physical examination and take care of their feet on a daily basis. They can also teach patients about the importance of regular visits to the clinic, blood tests at specified intervals and the primary principle of diabetes care and prevention of its complication [17].

\subsection{Significance of the Study}

Egypt is one of the 19 countries and territories of the international diabetes federation (IDF) MENA region. 425 million people have diabetes in the world and more than 39 million people in the MENA Region; by 2045 this will rise to 67 million. There were 8.222.600 cases of diabetes in Egypt in 2017 [19]. Diabetes can cause number of severe complications that increase morbidity, mortality and healthcare cost, Diabetic foot complications are the most common occurring problems throughout the globe, where diabetic foot ulcers (DFUs) have a neuropathic origin with a progressive prevalence rate in developing countries compared with developed countries among diabetes mellitus patients. Which is considered an irreversible, costly and incapacitating complication with severe physical, mental and social consequences [23]. Besides, [1] who studied the Effectiveness of health education intervention on foot self-care practice among diabetics at Zagazig University suggested in their study that Targeted health education programs regarding foot care strategies for diabetic patients are needed to reduce diabetic foot complications and ultimately amputation. So the current study was conducted in order to assess the effectiveness of health education program regarding foot self-care on risk for developing foot ulcer among patients with diabetes

\subsection{Aim of the Study}

The aim of the present study was to evaluate the effectiveness of health education program regarding foot self-care on risk for developing foot ulcer among patients with diabetes

It was done through:

1. Assessing level of knowledge regarding foot self-care among patients with diabetes.

2. Determining degree of self-efficacy and foot care behavior among patients with diabetes.

3. Assessing the risk of developing foot ulcer among patients with diabetes.

4. Designing, implementing the educational program and evaluating its effectiveness.

\subsection{Research Hypotheses}

To fulfill the aim of this study the following research hypotheses were formulated:

H1- The intervention group with diabetes who received self-care educational program will exhibit significantly higher level of knowledge post program compared to control group.

H2- Mean score of self-efficacy among the intervention group with diabetes post program implementation will be significantly higher compared to control group

H3- There will be significant difference with higher degree of foot care behavior post program implementation among the intervention group compared to control group

H4- The risk of developing foot ulcer will be significantly lower among intervention group compared to control group post program implementation.

\section{Subjects and Methods}

\subsection{Research Design}

Quasi-experimental design was utilized to conduct the current study.

\subsection{Study Setting}

This study was conducted in diabetes unit involved in medical departments then; it was completed at outpatient clinics during their follow up at Benha University Hospital.

\subsection{Subjects}

\subsubsection{Type}

Purposive sampling technique was used to select the samples.

\subsubsection{Size}

The sample size was calculated based on the previous year census report of admission in diabetes unit [7]. The total number of subjects comprised 151 patients, utilizing the following formula [32].

$$
\mathrm{n}=\frac{N}{1+N(e)^{2}}
$$


Where:

$\mathrm{n}=$ sample size

$\mathrm{N}=$ total population $(241)$

$\mathrm{e}=$ margin error $(0.05)$

A total 151 of patients were recruited in the current study.

They were divided into two groups using block randomization:
Group (1) control group included 76 patients they had ordinary nursing care. Group (2) intervention group included 75 patients they had the self-care educational program, to reach at the end of study period to 68 patients in the control group and 64 patients in the intervention group with final total of (132 patients).

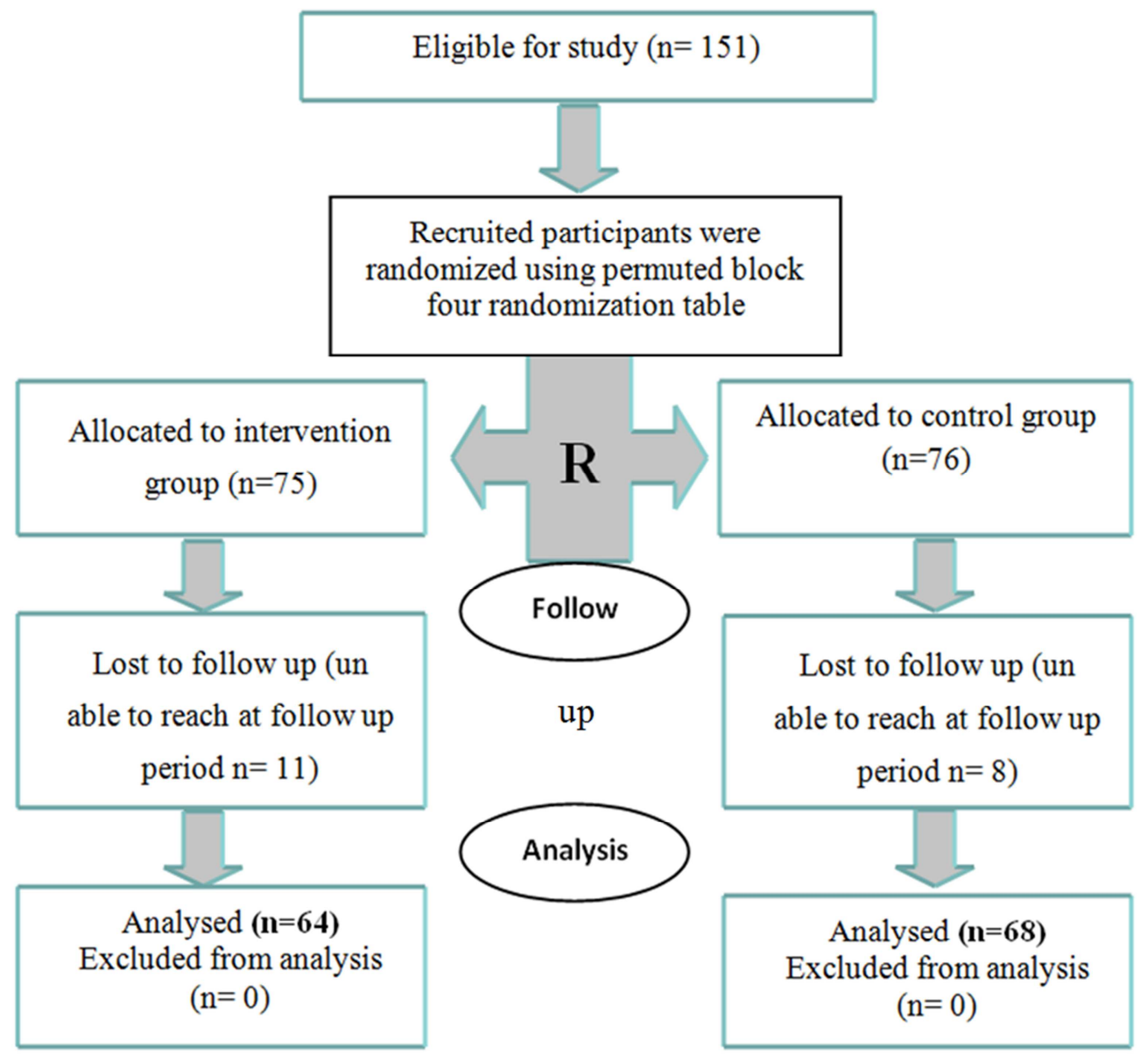

Figure 1. The process of study design.

\subsubsection{Technique}

Where participants are randomly assigned with equal probability to group A or B by choosing one paper of two blindly, one half of participants was assigned to (A) and the other half to $(B)$. In block size 4 , there are six combinations of group assignments: $\mathrm{AABB}, \mathrm{ABAB}, \mathrm{BAAB}, \mathrm{BABA}, \mathrm{BBAA}$, and $\mathrm{ABBA}$. One of these arrangements is selected at random as listed before and the following participants are assigned accordingly. This process was repeated as many times as needed [14]. The most severe imbalance in the study group size that occurred was the difference of two [28], the patients had been selected according to the following criteria:

\subsubsection{Inclusion Criteria}

Adult patients, from both genders, aged 18 years or older, with the diagnosis of diabetes mellitus type 2, while excluded patients with history of previous or present foot ulcer, cognitive, and visual or hearing impairment, also had prior formal diabetes education.

\subsection{Tools of Data Collection}

Four tools were utilized for data collection.

\subsubsection{Tool I}

Structured interviewing questionnaire sheet: it was developed by the researchers, and was divided into three parts:

Part 1: Concerned with socio-demographic characteristics of the study subjects regarding; age, gender, marital status, residence, education level, occupation, nature of work, presence of care givers, and BMI.

Part 2: It aimed to assess patients' illness related data such as; family history, comorbid disease, last rate of glucose, time since diagnosis, associated problems with diabetes, and presence of foot problems, ..... etc.

Part 3: Structured Knowledge Questionnaire. It entails knowledge on foot care (KFC), developed by [8], It aimed to assess patients' knowledge, which comprised 15 Yes/No type questions focusing on diabetes foot complications, risk factors and the foot care for patient with diabetes, 
Knowledge scoring system: There were 15 Yes/No type questions, for each question the score was graded as (1) for correct response and (zero) mark for wrong response. Good knowledge patients have a score of $11-15(>70 \%)$, average patients with a score of $8-10(50-70 \%)$ and poor knowledge patients with a score of $<8(<50 \%)$, based on the scores patients are categorized as good, average and poor knowledge patients.

\subsubsection{Tool (II)}

The Foot Care Confidence Scale (FCCS), was developed by the study [29]. This scale was used to measure self-confidence in managing foot care. It consisted of 12 items. The scale given into five scores; strongly not confident (score 1) to strongly confident (5). Higher scores show high in self-confidence in managing foot care behavior.

\subsubsection{Tool (III)}

The Diabetes Foot Self-Care Behavior Scale (DFSBS), was developed by the study [10]. The DFSBS contains 16 items. Divided into two parts: In the first part, the responses will be rated on the number of days patients performed a certain behavior over the course of one week ( 0 for never, 7 for every day they performed the activity). In the second part, the responses will be rated by the frequency with which patients performed a certain behavior in general, from never (0) to always (5). The responses will be rated as a 5- point Likert scale [never/ 0 day per week (1), rarely/ 1-2 days per week (2), sometimes/ 3-4 days per week (3), often/ 5-6 days per week (4) and always/ 7 days per week (5)]. A higher score indicated good foot self-care behavior.

\subsubsection{Tool (IV)}

Inlow's 60-second Diabetic Foot Screen, adopted from [18]. This tool is designed to assist in screening persons with diabetes to prevent or treat diabetes-related foot ulcers and/or limb threatening complications. It was comprised from, look20 seconds for skin (0-3 score), nails (0-2 score), deformity (0-4 score), footwear (0-1 score). Touch 10 seconds for right $\&$ left foot for temperature (0-1 score for each leg) and range of motion 0- 3 score) and 30 seconds assessment for sensation for Monofilament site ( $0-4$ score) test sensation ask patient 4 questions:. (1-Are your feet ever numb? 2-Do they ever tingle? 3- Do they ever burn? 4- Do they ever feel like insects are crawling on them?), pedal pulses, erythema, dependent rubor. rInlow's 60-second Diabetic Foot Screen can also assist in determining patient risk. By reviewing the results from Inlow's 60-second Diabetic Foot Screen, the clinician can use the International Working Group on the Diabetic Foot (IWGDF) - Risk Classification System to identify a risk category for their patients [20].

International Working Group on the Diabetic Foot (IWGDF) - Risk Classification System criteria: 0 Normal no neuropathy 1 Loss of protective sensation (LOPS) 2 a LOPS and deformity $2 b$ Peripheral arterial disease $3 a$ Previous hx of ulceration $3 b$ Previous $h x$ of amputation Scoring system: Screening for foot ulcers and/or limb-threatening complications. Score $=0$ to 6 recommend screening yearly, Score $=7$ to 12 recommend screening every 6 months Score $=13$ to 19 recommend screening every 3 months. Score 20 to 25 recommend screening every month.

\subsubsection{Tool Validity}

The content validity was done through five panels of experts in medical and nursing fields and their opinions were requested via an assessment form. The experts were asked to grade each item as "essential," "useful but inadequate" or "unnecessary", and modifications were carried out according to experts' judgment on the clarity and content appropriateness. The percentage of consensus among experts regarding, Structured knowledge questionnaire was $96 \%$ and The foot care confidence Scale was 97\%, The Diabetes Foot Self-Care Behavior Scale was $97 \%$ and inlow's 60-second Diabetic Foot Screen was $98 \%$.

\subsubsection{Ethical Considerations}

This study was conducted under the approval of Ethics Committee in the Faculty of Nursing, Benha University. An explanation about the purpose of the study was given to participants, and they were also informed that they could withdraw from the study at any time before the completion of the study. After agreement for Participation in the study, participants were asked to sign a consent form. Moreover, they were reassured that all information gathered would be confidential and used only for the purpose of the study.

\subsubsection{Pilot Study}

It was conducted on $10 \%$ of the total sample (15 patients) with diabetes mellitus, and they were excluded from the study sample. In order to test the feasibility and reliability of tools, and the necessary modifications were done prior data collection. Regarding cronbach's alpha value for Structured knowledge questionnaire was $0.97 \%$, foot care confidence Scale was $0.92 \%$, The Diabetes Foot Self-care Behavior Scale Internal consistency was acceptable (Cronbach's alpha $=0.73$ ), In addition inlow's 60-second Diabetic Foot Screen related intraclass correlation coefficient was (2.1).

\subsection{Field of Work}

Data were collected in the following sequence

i An official permission to carry out the study was obtained from pertinent authorities of diabetes unit involved in medical departments and outpatient clinics at Benha university hospital and by the submission of a formal letters from the Faculty of Nursing, Benha University after explanation of its purpose. Then, structured interview was conducted for eligible subjects in this study (fulfilled the inclusion and exclusion criteria) in order to explain the purpose of the study, assure confidentiality and to obtain informed written consent.

ii Data collection extended over a period of 9 months from beginning of September 2018 to beginning of June 2019. Procedures:

The self-care educational program comprised the following 
phases:

\subsubsection{Assessment Phase}

Hospitalized patients due to uncontrolled blood glucose level were interviewed before applying the program in order to collect the baseline patients' data using all study tools. This interview took about 30 to 35 minutes.

\subsubsection{Implementation Phase}

The self-care educational program was implemented for patients assigned to intervention group, while they were in diabetes unit, where educational sessions and small group discussion were held. It was covered in 4 sessions. The first session was carried out during assessment phase, involved (types of diabetes, awareness of risk factors of diabetic foot, its causes, and complications, signs \& symptoms), and the second session involved (importance of controlling diet, quitting smoking and achieving glycemic control as part of the prevention of diabetic foot development), while the third involved (hygiene and inspection, skin and nail care, appropriate footwear, injury prevention, and when to seek a healthcare professional). Also the fourth session included (examining foot and shoes as well as foot exercises). Each session took about 25 to 30 minutes.

The instructional booklet was given to each patient under the study as well as care givers were involved in order to help for reviewing and support teaching at home, and teaching materials which were used in these sessions included illustrations, models and discussions. It was developed by the researcher based on review of current literature. A booklet containing the content of self-care program, it was written in a simple Arabic language and supplemented by photos and illustrations to help the patient understanding of the content.

\subsubsection{Evaluation Phase}

Immediately after implementation of the self-care educational program, each patient in the study was interviewed to evaluate their knowledge using tool (I, Part 3) (Structured knowledge questionnaire).

After one month from implementation of the intervention, evaluation of patients was done on basis of foot care confidence, and foot care behavior using the study tools (II, III).

After three months from implementation of the intervention, evaluation of patients was done on basis of knowledge, foot care confidence, and foot care behavior using the study tools $\{$ I (Part 3), II, \& III $\}$.

After six months, from implementation of the intervention, study subjects were reevaluated by the researcher on basis of knowledge, foot care confidence, foot care behavior, and patients screening with diabetes using the study tools \{I (Part 3), II, \& III, IV \}.

\subsubsection{Data Analysis}

The collected data were tabulated and statistically analyzed using an IBM computer and the statistical package for social science (SPSS) advanced statistics, version 20 (SPSS Inc., Chicago, IL). Numerical data were expressed as mean and standard deviation. Qualitative data were expressed as frequency and percentage. Chi-square test was used to examine the relation between qualitative variables. For quantitative data, comparison between two groups was done using student t-test. One-way ANOVA for repeated measures at different time intervals in each group was done. Linear regression was used for multivariate analyses on risk of developing foot ulcer as dependent factors. A p-value $<0.05$ was considered significant, and $<0.001$ was considered highly significant.

\section{Results}

Table 1 Points out that there was no significant statistical difference between both (control \&intervention groups) regarding their sociodemographic characteristics, with a mean age of $(45.60 \pm 10.60 \& 45.38 \pm 10.73$, respectively) and more than two thirds $(70.6 \% \& 70.3 \%$, respectively) of both groups were male as well as, $(73.5 \% \& 76.6 \%$, respectively) were married, more over ( $55.9 \% \& 57.8$, respectively) were residing in urban area, and around two fifths of them $(41.2 \%$ $\& 42.2 \%$, respectively) were illiterate, besides, had a free work in about (45.6\% \& $42.2 \%$, respectively), which requires moderate effort in about more than half $(55.9 \%$ \& $57.8 \%$, respectively), besides, (70.6 \% \& $70.3 \%$, respectively), of them had care givers, more over their mean BMI was ( $28.96 \pm 0.57 \& 28.95 \pm 0.56$, respectively).

Table 2 Clarifies that there was no significant statistical difference between both (control \& intervention groups) regarding their illness related data, with more than half (55.9\% \& 57.8\%, respectively) had a family history with diabetes, with presence of hypertension among more than two thirds of both groups, and a high mean rate of blood glucose which was $(229.41 \pm 23.30 \& 234.06 \pm 27.75$, respectively) in more than half of patients surviving with diabetes for less than 5 years, with is often associated with high blood glucose among (70.6\% \& $70.3 \%$, respectively) also ( $85.3 \%$ \& $85.9 \%$, respectively) were complaining with numbness in their foot besides the same percent not comply with diabetic diet and approximating percent $(85.3 \%$ \& $84.4 \%$, respectively) receiving oral hypoglycemic therapy.

Table 3 Reveals that, there was no significant statistical difference between both groups regarding their level of knowledge about foot care, to be a highly statistically significantly different during measurement periods during (immediate post, after three and six months) of program implementation.

Figure 2 Portrays the significant difference in mean knowledge scores within each group through different study periods $(\mathrm{p} \leq 0.001 * *)$

Table 4 Indicates that, there was no significant statistical difference between both groups regarding their score of foot care confidence before program implementation, to be highly statistically significantly different after one, three and six months of program implementation in term of improvement in efficacy score among the intervention group than in control group. It also reveals the significant 
difference within intervention group through different study periods $\left(\mathrm{p} \leq 0.001^{* *}\right)$, with no significant difference within control group.

Table 5 Points out that, there was no significant statistical difference between both groups regarding their behavior score before program implementation, to be highly statistically significantly different after one, three and six months of program implementation in term of improvement in behavior score among the intervention group than in control group. It also reveals the significant difference within intervention group through different study periods in both groups $(\mathrm{p} \leq 0.001 * *)$.

Table 6 Shows that, there was no significant statistical difference between both groups regarding their foot status before program implementation, to be highly statistically significantly different after 6 months of program implementation in term of higher degree of risk among the control group which was reflected by its higher score than among intervention group.

Table 7 Reflects a significant statistical difference between both groups regarding their foot status which was screened after 6 months through looking at the skin, nails, deformity and foot wear, as well as through touch in order to detect the temperature and range of motion, but there is no significant difference regarding assessing its status for sensation, pulses, dependent rubor and erythema., but still at greater risk among control group than in intervention group.

Figure 3 Illustrates that $44.1 \%$ of control group had high risk for diabetic foot (Loss of protective sensation, loss of protective sensation and deformity, peripheral arterial disease and past history of ulceration), while $12.5 \%$ of intervention group only had loss of protective sensation.

Table 8 Presents that the risk of developing diabetic foot ulcer (high risk) among control group was best predicted by subjects' BMI accounting for $46.0 \%$ of the risk for its development.

Table 9 Presents that the risk of developing diabetic foot ulcer (low risk) among intervention group was best predicted by subjects' BMI, nature of their work, level of knowledge regarding foot care as well as foot care behavior accounting for $100.0 \%$ of the risk for its development.

Table 1. Number and percentage distribution of both studied groups according to their socio-demographic characteristics, control group (n=68) and intervention group $(n=64)$.

\begin{tabular}{|c|c|c|c|c|c|}
\hline \multirow{2}{*}{$\begin{array}{l}\text { Sociodemographic } \\
\text { characteristics }\end{array}$} & \multicolumn{2}{|c|}{ Control group $(n=68)$} & \multicolumn{2}{|c|}{ Intervention group $(n=64)$} & \multirow{2}{*}{$\begin{array}{l}\text { chi square } \\
\text { p-value } \\
\end{array}$} \\
\hline & (No.) & $\%$ & (No.) & $\%$ & \\
\hline \multicolumn{6}{|l|}{ *Age } \\
\hline$<40$ years & 18 & 26.5 & 18 & 28.1 & 0.548 \\
\hline $40-<60$ years & 40 & 58.8 & 37 & 57.8 & $0.999^{\text {n.s }}$ \\
\hline $60 \geq$ years & 10 & 14.7 & 9 & 14.1 & \\
\hline Mean \pm SD & \multicolumn{2}{|l|}{$45.60 \pm 10.60$} & \multicolumn{2}{|l|}{$45.38 \pm 10.73$} & $\begin{array}{l}\mathrm{t} \text { test }=-0.123 \\
\mathrm{p} \text { value }=0.903^{\mathrm{n} . \mathrm{s}}\end{array}$ \\
\hline \multicolumn{6}{|l|}{ *Gender } \\
\hline Male & 48 & 70.6 & 45 & 70.3 & 0.001 \\
\hline Female & 20 & 29.4 & 19 & 29.7 & $0.972^{\text {n.s }}$ \\
\hline \multicolumn{6}{|l|}{ *Marital status } \\
\hline Not married & 18 & 26.5 & 15 & 23.4 & 0.045 \\
\hline Married & 50 & 73.5 & 49 & 76.6 & $0.831^{\text {n.s }}$ \\
\hline \multicolumn{6}{|l|}{ *Residence } \\
\hline Rural & 30 & 44.1 & 27 & 42.2 & 0.05 \\
\hline Urban & 38 & 55.9 & 37 & 57.8 & $0.823^{\text {n.s }}$ \\
\hline \multicolumn{6}{|l|}{ *Level of education } \\
\hline Illiterate & 28 & 41.2 & 27 & 42.2 & 0.028 \\
\hline Primary & 0 & 0 & 0 & 0 & $0.986^{\text {n.s }}$ \\
\hline Secondary & 20 & 29.4 & 19 & 29.7 & \\
\hline University & 20 & 29.4 & 18 & 28.1 & \\
\hline \multicolumn{6}{|l|}{ *Occupation } \\
\hline Employee & 27 & 39.7 & 23 & 35.9 & 1.142 \\
\hline Free work & 31 & 45.6 & 27 & 42.2 & $0.565^{\text {n.s }}$ \\
\hline Housewife & 10 & 14.7 & 14 & 21.9 & \\
\hline \multicolumn{6}{|l|}{ *Nature of work } \\
\hline Simple & 10 & 14.7 & 9 & 14.1 & 0.05 \\
\hline Moderate & 38 & 55.9 & 37 & 57.8 & $0.975^{\text {n.s }}$ \\
\hline Heavy work & 20 & 29.4 & 18 & 28.1 & \\
\hline \multicolumn{6}{|c|}{ *Presence of caregivers } \\
\hline No & 20 & 29.4 & 19 & 29.7 & 0.001 \\
\hline Yes & 48 & 70.6 & 45 & 70.3 & $0.972^{\text {n.s }}$ \\
\hline \multicolumn{6}{|l|}{ *BMI } \\
\hline$<30 \mathrm{k} / \mathrm{m}^{2}$ & 58 & 85.3 & 55 & 85.9 & 0.055 \\
\hline$\geq 30 \mathrm{k} / \mathrm{m}^{2}$ & 10 & 14.7 & 9 & 14.1 & $1.000^{\text {n.s }}$ \\
\hline Mean \pm SD & $28.96 \pm 0.57$ & & $28.95 \pm 0.56$ & & $\begin{array}{l}\mathrm{t} \text { test }=-0.040 \\
\mathrm{p} \text { value }=0.968^{\mathrm{n} . \mathrm{s}}\end{array}$ \\
\hline
\end{tabular}

(n.s) not significant (BMI) Body Mass Index 
Table 2. Number and percentage distribution of both studied groups according to their illness related data, control group ( $n=68)$ and intervention group $(n=$ 64).

\begin{tabular}{|c|c|c|c|c|c|}
\hline \multirow{2}{*}{ Illness related data } & \multicolumn{2}{|c|}{ Control group $(n=68)$} & \multicolumn{2}{|c|}{ Intervention group $(n=64)$} & \multirow{2}{*}{$\begin{array}{l}\text { chi square } \\
\text { p- value }\end{array}$} \\
\hline & (No.). & $\%$ & (No.). & $\%$ & \\
\hline \multicolumn{6}{|c|}{ *Family history of diabetes mellitus } \\
\hline No & 30 & 44.1 & 27 & 42.2 & 0.050 \\
\hline Yes & 38 & 55.9 & 37 & 57.8 & $0.823^{\text {n.s }}$ \\
\hline \multicolumn{6}{|l|}{ *Smoking } \\
\hline No & 30 & 44.1 & 28 & 43.7 & \multirow{4}{*}{$\begin{array}{l}0.019 \\
0.991^{\text {n.s }}\end{array}$} \\
\hline Yes but stopped & 28 & 41.2 & 27 & 42.2 & \\
\hline Yes & 10 & 14.7 & 9 & 14.1 & \\
\hline \multicolumn{5}{|c|}{ *Presence of co morbid disease \# } & \\
\hline No & 10 & 14.7 & 9 & 14.1 & $\begin{array}{l}0.011 \\
0.916^{\text {n.s }}\end{array}$ \\
\hline Hypertension & 48 & 70.6 & 45 & 70.3 & $\begin{array}{l}0.001 \\
0.972^{n . s}\end{array}$ \\
\hline Thyroid disease & 10 & 14.7 & 10 & 15.6 & $\begin{array}{l}0.022 \\
0.883^{\text {n.s }}\end{array}$ \\
\hline Renal disease & 10 & 14.7 & 9 & 14.1 & $\begin{array}{l}0.011 \\
0.916^{\mathrm{n} . \mathrm{s}}\end{array}$ \\
\hline \multicolumn{6}{|c|}{ *Last rate of blood glucose } \\
\hline Mean \pm SD & \multicolumn{2}{|l|}{$229.41 \pm 23.30$} & \multicolumn{2}{|l|}{$234.06 \pm 27.75$} & $\begin{array}{l}\mathrm{t} \text { test }=-0.072 \\
\mathrm{p} \text { value }=0.943^{\mathrm{n} . \mathrm{s}}\end{array}$ \\
\hline \multicolumn{6}{|l|}{ *Time since diagnosis } \\
\hline$<5$ years & 38 & 55.9 & 36 & 56.2 & \multirow{3}{*}{$\begin{array}{l}0.002 \\
0.966^{\text {n.s }}\end{array}$} \\
\hline 5 years $-<10$ years & 27 & 39.7 & 22 & 34.4 & \\
\hline$\geq 10$ years & 3 & 4.4 & 6 & 9.4 & \\
\hline Mean \pm SD & $1.44 \pm 0.50$ & & $1.43 \pm 0.50$ & & $\begin{array}{l}\mathrm{t} \text { test }=-0.042 \\
\mathrm{p} \text { value }=0.966^{\text {n.s }}\end{array}$ \\
\hline \multicolumn{6}{|c|}{ *Associated problems with diabetes } \\
\hline High blood glucose & 48 & 70.6 & 45 & 70.3 & 0.001 \\
\hline $\begin{array}{l}\text { Neuropathy } \\
\text { *Presence of foot pro }\end{array}$ & \multicolumn{4}{|c|}{ *Presence of foot problems \# } & $0.972^{\text {n.s }}$ \\
\hline Claudication & 20 & 29.4 & 19 & 29.7 & $\begin{array}{l}0.001 \\
0.972^{\text {n.s }}\end{array}$ \\
\hline Numbness & 58 & 85.3 & 55 & 85.9 & $\begin{array}{l}0.011 \\
0.916^{\text {n.s }}\end{array}$ \\
\hline \multicolumn{6}{|c|}{${ }^{*}$ Comply with diabetic diet } \\
\hline No & 58 & 85.3 & 55 & 85.9 & 0.011 \\
\hline Yes but stopped & 10 & 14.7 & 9 & 14.1 & $0.916^{\text {n.s }}$ \\
\hline \multicolumn{6}{|l|}{ *Medication } \\
\hline Insulin & 10 & 14.7 & 10 & 15.6 & 0.022 \\
\hline Tablet & 58 & 85.3 & 54 & 84.4 & $0.883^{\text {n.s }}$ \\
\hline
\end{tabular}

(n.s) not significant

(\#) not mutually exclusive

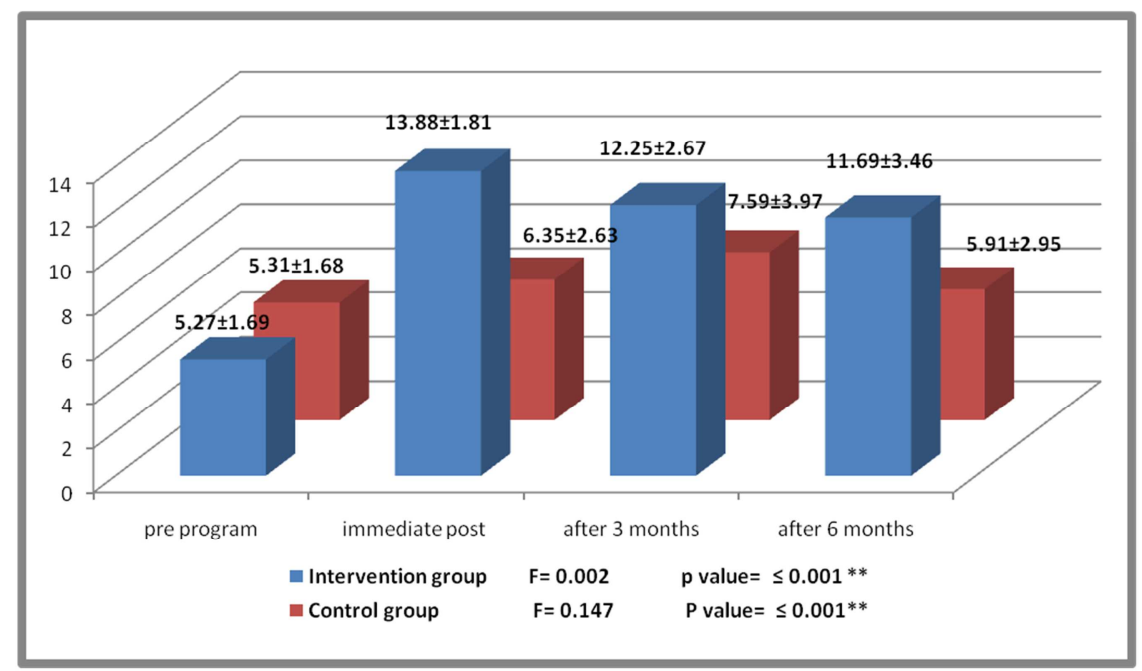

Figure 2. Mean differences of knowledge scores within each group throughout study periods. 
Table 3. Differences in level of knowledge between both studied groups throughout measurement periods (pre program, after one month, after 3 months, and after 6 months of program implementation) \{control group $(n=68) \&$ intervention group $(n=64)\}$.

\begin{tabular}{|c|c|c|c|c|}
\hline \multirow{3}{*}{$\begin{array}{l}\text { Patients' Knowledge about } \\
\text { foot care }\end{array}$} & \multicolumn{4}{|c|}{ Control group $(n=68)$} \\
\hline & Pre program & Immediate Post program & After 3 months & After 6 months \\
\hline & No(\%) & No(\%) & No(\%) & No(\%) \\
\hline average & $3(4.4 \%)$ & $28(41.2 \%)$ & $29(42.6 \%)$ & $28(41.2 \%)$ \\
\hline Good & $0(0.0 \%)$ & $0(0.0 \%)$ & $9(13.2 \%)$ & $0(0.0 \%)$ \\
\hline
\end{tabular}

Table 3. Continued.

\begin{tabular}{|c|c|c|c|c|c|c|c|c|}
\hline \multirow{3}{*}{$\begin{array}{l}\text { Patients' } \\
\text { Knowledge } \\
\text { about foot } \\
\text { care }\end{array}$} & \multicolumn{4}{|c|}{ Intervention group $(n=64)$} & \multirow{3}{*}{$\begin{array}{l}\text { Chi-square } \\
\text { (p value) (1) }\end{array}$} & \multirow{3}{*}{$\begin{array}{l}\text { Chi-square } \\
\text { (p value) (2) }\end{array}$} & \multirow{3}{*}{$\begin{array}{l}\text { Chi-square } \\
\text { (p value) (3) }\end{array}$} & \multirow{3}{*}{$\begin{array}{l}\text { Chi-square } \\
\text { (p value) (4) }\end{array}$} \\
\hline & Pre program & $\begin{array}{l}\text { Immediate } \\
\text { Post program }\end{array}$ & $\begin{array}{l}\text { After } 3 \\
\text { months }\end{array}$ & $\begin{array}{l}\text { After } 6 \\
\text { months }\end{array}$ & & & & \\
\hline & No(\%) & No(\%) & No(\%) & No(\%) & & & & \\
\hline Poor & $59(92.2 \%)$ & $0(0.0 \%)$ & $0(0.0 \%)$ & $9(14.1 \%)$ & & & & \\
\hline average & $5(7.8 \%)$ & $0(0.0 \%)$ & $23(35.9 \%)$ & $19(29.7 \%)$ & 0.67 & 132 & 51.098 & 57.267 \\
\hline Good & $0(0.0 \%)$ & $64(100.0 \%)$ & $41(64.1 \%)$ & $36(56.2 \%)$ & $0.413^{\mathrm{n} . \mathrm{s}}$ & $<0.001^{* *}$ & $<0.001^{* *}$ & $<0.001^{* *}$ \\
\hline
\end{tabular}

(n.s) not significant (**) Highly statistically significant at $\leq 0.001$

(1) Difference in level of knowledge before program implementation between both control and intervention groups.

(2) Difference in level of knowledge during immediate post program implementation between both control and intervention groups.

(3) Difference in level of knowledge after 3 months of program implementation between both control and intervention groups.

(4) Difference in level of knowledge after 6 months of program implementation between both control and intervention groups.

Table 4. Mean differences in foot care confidence scores between both studied groups throughout measurement periods (pre program, after one month, after 3 months, and after 6 months of program implementation). \{control group $(n=68)$ and intervention group $(n=64)\}$.

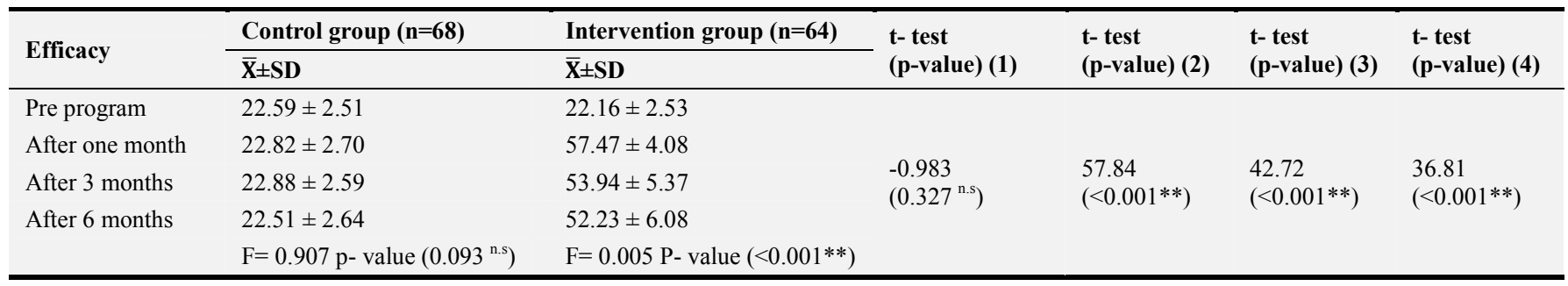

(n.s) not significant $(* *)$ Highly statistically significant at $\leq 0.001$

(1) Mean difference in efficacy score before program implementation between both control and intervention groups

(2) Mean difference in efficacy score after 1 month of program implementation between both control and intervention groups

(3) Mean difference in efficacy score after 3 months of program implementation between both control and intervention groups

(4) Mean difference in efficacy score after 6 months of program implementation between both control and intervention groups

Table 5. Mean differences in behavior scores between both studied groups throughout measurement periods (pre program, after 3 months, and after 6 months of program implementation control group $(n=68)$ and intervention group $(n=64)\}$.

\begin{tabular}{|c|c|c|c|c|c|c|}
\hline \multirow{2}{*}{ Behavior } & Control group $(n=68)$ & Intervention group $(n=64)$ & \multirow{2}{*}{$\begin{array}{l}\text { t- test } \\
\text { (p-value) (1) }\end{array}$} & \multirow{2}{*}{$\begin{array}{l}\text { t- test } \\
\text { (p-value) (2) }\end{array}$} & \multirow{2}{*}{$\begin{array}{l}\text { t- test } \\
\text { (p-value) (3) }\end{array}$} & \multirow{2}{*}{$\begin{array}{l}\text { t- test } \\
\text { (p-value) }\end{array}$} \\
\hline & $\overline{\mathbf{X}} \pm$ SD & $\overline{\mathbf{X}} \pm$ SD & & & & \\
\hline Pre program & $27.47 \pm 6.33$ & $28.00 \pm 5.87$ & \multirow{5}{*}{$\begin{array}{l}0.498 \\
\left(0.620^{\text {n.s }}\right)\end{array}$} & \multirow{5}{*}{$\begin{array}{l}33.164 \\
\left(<0.001^{* *}\right)\end{array}$} & \multirow{5}{*}{$\begin{array}{l}24.015 \\
(<0.001 * *)\end{array}$} & \multirow{5}{*}{$\begin{array}{l}20.764 \\
\left(<0.001^{* *}\right)\end{array}$} \\
\hline After 3 months & $47.01 \pm 7.95$ & $82.06 \pm 8.81$ & & & & \\
\hline \multirow[t]{3}{*}{ After 6 months } & $46.60 \pm 8.49$ & $80.23 \pm 10.09$ & & & & \\
\hline & $\mathrm{F}=0.094$ & $\mathrm{~F}=0.002$ & & & & \\
\hline & P-value $(<0.001 * *)$ & P- value $\left(<0.001^{* *}\right)$ & & & & \\
\hline
\end{tabular}

(n.s) not significant (**) Highly statistically significant at $\leq 0.001$

(1) Mean difference in behavior score before program implementation between both control and intervention groups.

(2) Mean difference in behavior score after 1 month of program implementation between both control and intervention groups.

(3) Mean difference in behavior score after 3 months of program implementation between both control and intervention groups.

(4) Mean difference in behavior score after 6 months of program implementation between both control and intervention groups. 
Table 6. Mean differences in total foot status scores regarding developing diabetic foot ulcer between both studied groups $\}$ throughout measurement periods (pre program and after 6 months of program implementation \{control group ( $n=68)$ and intervention group $(n=64)$.

\begin{tabular}{|c|c|c|c|c|}
\hline \multirow{2}{*}{ Inlow's 60-second Diabetic Foot Screen } & Control group $(\mathrm{n}=68)$ & Intervention group $(n=64)$ & \multirow{2}{*}{$\begin{array}{l}\text { t- test (p-value) } \\
\text { (1) }\end{array}$} & \multirow{2}{*}{$\begin{array}{l}\text { t- test (p-value) } \\
\text { (2) }\end{array}$} \\
\hline & $\overline{\mathbf{X}} \pm \mathrm{SD}$ & $\overline{\mathbf{X}} \pm \mathbf{S D}$ & & \\
\hline Pre program & $0.58 \pm 0.91$ & $0.59 \pm 0.92$ & 0.034 & -2.065 \\
\hline After 6 months & $2.13 \pm 3.19$ & $1.18 \pm 1.84$ & $\left(0.973^{\text {n.s }}\right)$ & $(0.041 *)$ \\
\hline
\end{tabular}

(n.s) not significant $(*)$ Statistically significant at $\leq 0.05$

(1) Mean difference in depression score before program implementation between both control and intervention groups.

(2) Mean difference in depression score after 6 months of program implementation between both control and intervention group.

Table 7. Mean differences in foot status scores regarding developing diabetic foot ulcer between both studied groups after 6 months of program implementation $\{$ control group $(n=68)$ and intervention group $(n=64)\}$.

\begin{tabular}{|c|c|c|c|c|}
\hline \multirow{2}{*}{$\begin{array}{l}\text { Inlow's 60-second Diabetic Foot } \\
\text { Screen after } 6 \text { months }\end{array}$} & Control group $(n=68)$ & Intervention group $(n=64)$ & \multirow{2}{*}{ t- test } & \multirow{2}{*}{ p-value } \\
\hline & $\overline{\mathbf{X}} \pm$ SD & $\overline{\mathbf{X}} \pm$ SD & & \\
\hline Look -20 seconds & $0.38 \pm 1.27$ & $0.00 \pm 0.00$ & \multirow{5}{*}{-2.408} & \multirow{5}{*}{$0.017 *$} \\
\hline Skin & $0.12 \pm 0.37$ & $0.00 \pm 0.00$ & & \\
\hline Nails & $0.12 \pm 0.37$ & $0.00 \pm 0.00$ & & \\
\hline Deformity & $0.03 \pm 0.24$ & $0.00 \pm 0.00$ & & \\
\hline Foot wear & $0.12 \pm 0.37$ & $0.00 \pm 0.00$ & & \\
\hline Touch -10 seconds & $0.41 \pm 0.76$ & $0.00 \pm 0.00$ & \multirow{4}{*}{-4.346} & \multirow{4}{*}{$<0.001 * *$} \\
\hline Temperature - cold & $0.10 \pm 0.31$ & $0.00 \pm 0.00$ & & \\
\hline Temperature - hot & $0.00 \pm 0.00$ & $0.00 \pm 0.00$ & & \\
\hline Range of motion & $0.31 \pm 0.72$ & $0.00 \pm 0.00$ & & \\
\hline Assess -30 seconds & $1.34 \pm 1.83$ & $1.19 \pm 1.84$ & \multirow{6}{*}{-0.472} & \multirow{6}{*}{$0.638^{\text {n.s }}$} \\
\hline Sensation - Monofiament Testing & $0.82 \pm 1.05$ & $0.28 \pm 0.70$ & & \\
\hline Sensation - Ask 4 Questions & $0.50 \pm 0.87$ & $0.59 \pm 0.92$ & & \\
\hline Pedal Pulses & $0.31 \pm 0.73$ & $0.00 \pm 0.00$ & & \\
\hline Erythema & $0.01 \pm 0.12$ & $0.00 \pm 0.00$ & & \\
\hline Dependent Rubor & $0.00 \pm 0.00$ & $0.00 \pm 0.00$ & & \\
\hline Total & $2.13 \pm 3.19$ & $1.18 \pm 1.84$ & -2.065 & $0.041 *$ \\
\hline
\end{tabular}

(n.s) not significant $(*)$ Statistically significant at $\leq 0.05(* *)$ Highly statistically significant at $\leq 0.001$

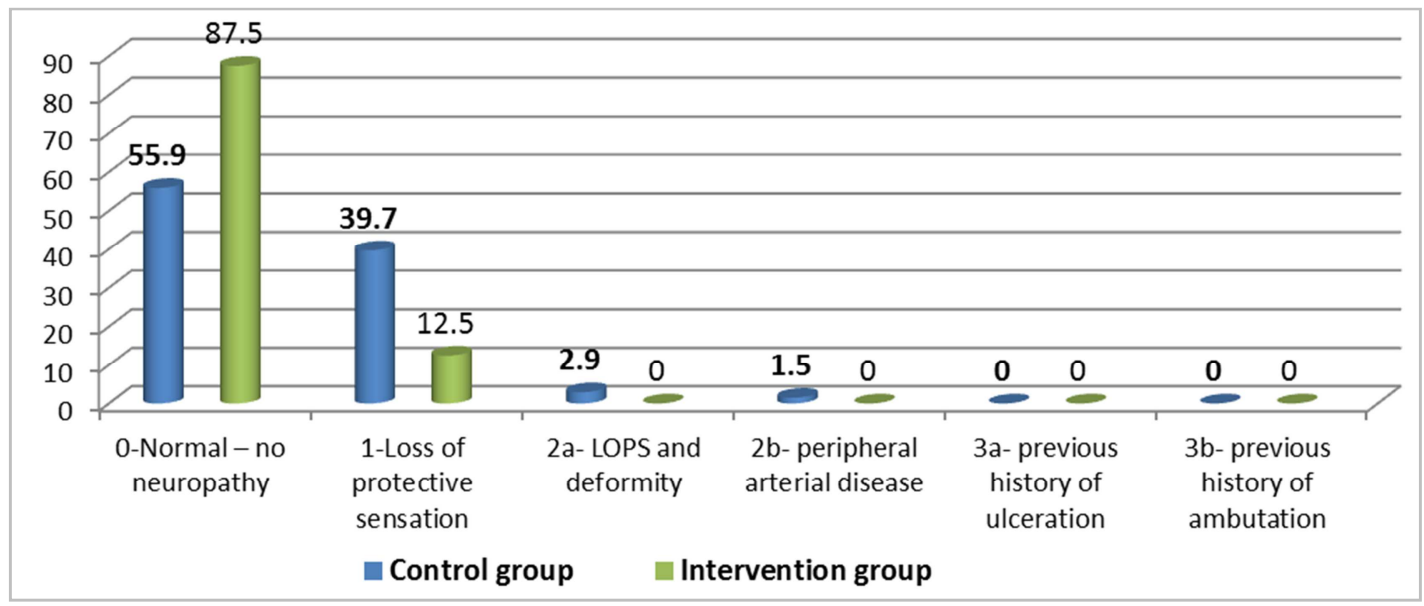

Figure 3. Risk classification of the studied groups by International Working Group on the Diabetic Foot (IWGDF) after six months.

Table 8. Multiple linear regression analyses for predictor variables of foot status involving the risk for developing foot ulcer among control group ( $n=68$ ).

\begin{tabular}{|c|c|c|c|c|c|}
\hline \multirow{2}{*}{ Predictor Variable } & \multicolumn{2}{|c|}{ Unstandardized Coefficients } & \multirow{2}{*}{$\begin{array}{l}\text { Standardized Coefficients } \\
\beta\end{array}$} & \multirow{2}{*}{$T$} & \multirow[b]{2}{*}{ p value } \\
\hline & B & SEB & & & \\
\hline Age & $-.115-$ & .098 & $-.382-$ & $-1.181-$ & .242 \\
\hline Marital status & 2.597 & 1.806 & .361 & 1.438 & .156 \\
\hline Presence of caregivers & $-2.248-$ & 1.215 & $-.323-$ & $-1.850-$ & .069 \\
\hline BMI & 2.909 & 1.397 & .521 & 2.083 & $.041 *$ \\
\hline Last level of blood glucose & $-.039-$ & .027 & $-.348-$ & $-1.481-$ & .144 \\
\hline Constant & $-68.327-$ & 34.833 & & $-1.962-$ & $.054 *$ \\
\hline Adjusted $\mathrm{R}^{2}=0.461 \mathrm{P}=0.010^{*}$ & & & & & \\
\hline
\end{tabular}

(BMI) Body mass index, (B) Beta Co-Efficient, (SEB) Standard Error, (BMI) body mass index 
Table 9. Multiple linear regression analyses for predictor variables of foot status involving the risk for developing foot ulcer among intervention group ( $n=64)$.

\begin{tabular}{|c|c|c|c|c|c|}
\hline \multirow{2}{*}{ Predictor Variable } & \multicolumn{2}{|c|}{ Unstandardized Coefficients } & \multirow{2}{*}{$\begin{array}{l}\text { Standardized Coefficients } \\
\beta\end{array}$} & \multirow{2}{*}{$T$} & \multirow{2}{*}{ p value } \\
\hline & B & SEB & & & \\
\hline Age & $6.153 \mathrm{E}-013$ & .000 & .000 & .000 & 1.000 \\
\hline Marital status & $-5.218 \mathrm{E}-012$ & .000 & .000 & .000 & 1.000 \\
\hline Nature of work & 2.136 & .000 & .741 & 2482360.859 & .000 \\
\hline BMI & 8.641 & .000 & 2.628 & 13206796.484 & .000 \\
\hline Level of foot care knowledge & $-4.922-$ & .000 & $-9.243-$ & $-15292991.087-$ & .000 \\
\hline Foot care behavior & 1.718 & .000 & 9.413 & 29877670.751 & .000 \\
\hline Adjusted $\mathrm{R}^{2}=1.000 \mathrm{P}=<0.001 * *$ & & & & & \\
\hline
\end{tabular}

(BMI) Body mass index, (B) Beta Co-Efficient, (SEB) Standard Error, (BMI) body mass index

\section{Discussion}

Diabetic foot problems are one of the most common chronic complications of diabetes that has a tremendous economic and social impact on individuals, families and on health system as a whole in developing and developed countries [24]. Improper foot care in diabetic patients can lead to many complications such as infection, ulcerations, gangrene and amputations [3]. So, this study aimed to evaluate the Effectiveness of health education program regarding foot self-care on risk for developing foot ulcer among patients with diabetes.

According to sociodemographic characteristics of the studied subjects, the present study results showed that, there were no significant statistical differences between both control \& intervention groups, revealing the homogeneity among study subjects regarding their characteristics, describing that the mean age of both control and study groups was $(45.60 \pm 10.60 \& 45.38 \pm 10.73$, respectively) and more than two thirds of both groups were male as well as, their mean BMI was $(28.96 \pm 0.57 \& 28.95 \pm 0.56$, respectively), and around half of them were residing in urban area, and illiterate and had a free work requires moderate effort. These findings were consistent with El-Sedawy [12] who found in their study about "Impact of Preventive Diabetic Foot Nursing Intervention on Foot Status among Patients with Diabetes". That the mean age of the study participants was $(49.2 \pm 11.1$ and $48.2 \pm 10.3$, respectively), the higher percent were males and married. Also, Al-Aboudi [2] found in their study about Knowledge, attitudes, and quality of life of type 2 diabetes patients that $(77.35 \%)$ respondents were male and $(45.3 \%)$ were in the age group of 45-55 years. While it was inconsistent with study findings [1] about "Effectiveness of health education intervention on foot self-care practice among diabetics" which revealed that Most of participant were residents of rural areas and $15.7 \%$ of them were of higher education. More than half of them were not working,

Concerning illness related data among both intervention and control groups, the present study revealed that there were no significant statistical differences between both groups also, with more than half of both groups had a family history with diabetes, with presence of hypertension among more than two thirds of both groups, and most of both groups receiving oral hypoglycemic therapy, also $(85.3 \%$ \& $85.9 \%$, respectively) were complaining with numbness in their foot.
These finding were in the same line with Sharoni [26] who stated in their study about "A self-efficacy education program on foot self-care behavior among older patients with diabetes in a public long term care institution" that most of them were on oral medication(s) (74.2\%), and had comorbid disease(s) $(93.5 \%)$. There were a high mean rate of blood glucose which was ( $229.41 \pm 23.30 \& 234.06 \pm 27.75$, respectively) and more than half of patients surviving with diabetes for less than 5 years. Also were congruent with Moussa [22] who revealed in their study about "Effect of Foot Self-care Program among Diabetic Elderly Adults in Geriatrics Home" that $(70.0 \%)$ of the study had family history of diabetes disease, As regard medical history $91.7 \%$ of the study had history of diseases such as hypertension $63.6 \%$. with reference to study findings of [13] about "Effects of a foot self-care educational intervention on improving footwear choices in those with type 2 diabetes at low risk of foot ulceration", they described that participants had diabetes for an average of $5.9 \pm 7.1$ years and the mean level of FPG and HbAlc suggested that the majority of participants did not reach the glycemic control targets.

Regarding level of knowledge between both studied (control and intervention groups) throughout measurement periods. The present study revealed that there were no significant statistical difference between both groups regarding their level of knowledge about foot care, to be a highly statistically significantly different during measurement periods (immediate post, after three and six months) of program implementation. It also revealed that there was a significant difference in mean knowledge score within each group through different study periods $(\mathrm{p} \leq$ $0.001 * *)$ which supported research hypothesis (1), assuring the effectiveness of the foot self-care educational program, and also indicating that, when the information is given to patients in a simplified way their knowledge improves. the poor of client' knowledge may be due to deficiency in the role played by mass media in reaching information and material about diabetic foot care and risk factors. These finding were congruent with [16] who stated in their study about "Diabetes education in primary care: a randomized clinical trial." that the score of knowledge on type 2 diabetes mellitus had increased in both groups, with a higher increase in the intervention group (baseline: $12 \pm 4.0$ vs. after 5-week: $15 \pm 3$ vs. 12-month: $16 \pm 3$ ); while control group (baseline: $12 \pm 3$ vs. after 5-week: $13 \pm 3$ vs. 12-month: 12 \pm 4 ), 
within-subjects $\mathrm{p}$-value $<0.001$ and between-groups $\mathrm{p}$-value $<0.001$. this means that knowledge scores improved after the intervention, also congruent with El-Sedawy [12] who found that, there was no statistically significant difference between mean scores of the control group $(11.7 \pm 4.2)$ and study group $(11.1 \pm 5.9)$ in the first visit regarding knowledge test. However, in the 4th visit, there was a statistically significant difference between mean scores of the control group (14.4 \pm $4.9)$ and study group $(20.9 \pm 3.5)$ with $\mathrm{t}$-test $=6.2$ at $\mathrm{p}$-value $=$ 0.000 .

In relation to self-efficacy scores between both studied groups. The present study pointed out that there were no significant statistical difference between both groups regarding their score of efficacy before program implementation, to be highly statistically significantly different after one, three and six months of program implementation in term of improvement in efficacy score among the intervention group than in control group, which supported research hypothesis (2). This might be due to the content of the educational program and the discussion of the studied subjects with the researchers helped to increase the self-efficacy of them, also following instructions provided during the educational program had appositive effect on improving their confidence while performing daily living activities. These findings were in the same line with Sharoni [26] who found that foot care self-efficacy (median=30.00), foot care outcome expectation (median=19.00) and knowledge of foot care scores (median=8.00) statistically increased from the baseline test to the evaluation test (foot care self-efficacy: median $=44.00, Z=-4.76, p<0.001$; foot care outcome expectation: median $=25.00, \quad Z=-4.79$, $\mathrm{p}<0.001$. Also [25] stated in their study about "Self-efficacy in foot care and effect of training: a single-blinded randomized controlled clinical trial." that there was no significant difference between the three groups regarding the mean of self-efficacy scores before foot-care training intervention $(\mathrm{P}=0.39)$. But, comparison of the scores before and after the intervention showed that both groups and individual training intervention increased the patients' self-efficacy $(\mathrm{P} \leq 0 / 05)$.

According to behavior scores between both studied groups. The current study demonstrated that there was no significant statistical difference between both groups regarding their behavior score before program implementation, to be highly statistically significantly different after one, three and six months of program implementation in term of improvement in behavior score among the intervention group than in control group. It also reveals the significant difference within intervention group through different study periods in both groups $\left(\mathrm{p} \leq 0.001^{* *}\right)$, which supported research hypothesis (3). This may be interpreted as the improved degree of self-confidence while performing daily living activities, had reflected on their behavior score. Moreover it considered a major predictor of successful self-care behavior in diabetes management because it will influences how people think, motivate themselves and act in order to modifying health behavior in the desired direction. These finding congruent with [24] who found in their study about "Impact of educational program about foot care on knowledge and self-care practice for diabetic older adult patients." that foot self-care practice after program implementation. Statistically highly significant difference was observed between both groups after implementation of the program. Also the study [22] revealed that there is a lack of knowledge as well as unsatisfactory practices of diabetic patients about self-care practice of foot before the program. However, after the program intervention, improvements were found in total scores of knowledge and practice. The improvements were maintained through the follow -up phase in total knowledge and total practices knowledge. Moreover, [27] had found while conducting the study about "The effects of self-efficacy enhancing program on foot self-care behavior of older adults with diabetes" that foot self-care behavior, foot care self-efficacy (efficacy expectation), foot care outcome expectation and knowledge of foot care scores significantly changed across the three time points $(p<0.01)$, the scores of the variables between the intervention and control groups were significantly different.

Regarding total foot status scores about developing diabetic foot ulcer between both studied groups. The study revealed that there was no significant statistical difference between both groups regarding their foot status before program implementation, to be highly statistically significantly different after 6 months of program implementation in term of higher degree of risk among the control group which was reflected by its higher score than among intervention group, which supported research hypothesis (4), pointing out the extended positive effect of program on foot care knowledge, self-efficacy, foot care behavior, and finally foot status in term of lowered risk for developing foot ulcer. These finding were in agreement with [26] who found that Foot condition improved significantly for overall foot hygiene $(p=0.03)$ and anhydrosis $(p=0.02)$ after the education program. [15] Reported in their study about "Beneficial effects of foot care nursing for people with diabetes mellitus: an uncontrolled before and after intervention study. " That application of a diabetic foot care program by a specialist nurse, which includes callus removal, demonstration of foot skin care practices and education, seems useful in preventing diabetic foot ulceration in high risk diabetics.

According to risk classification of the studied groups by International Working Group on the Diabetic Foot. The current study illustrated that $44.1 \%$ of control group had high risk for diabetic foot (Loss of protective sensation, or loss of protective sensation and deformity, or peripheral arterial disease and past history of ulceration), while $12.5 \%$ of intervention group only had loss of protective sensation. These finding were in the same line with [1] who found that show that $31.5 \%$ of studied patients had high risk for diabetic foot (Loss of protective sensation and deformity, peripheral arterial disease and past history of ulceration)

Concerning predictor variables of foot status involving the risk for developing foot ulcer among control group. The 
current study presented that the increased risk of developing diabetic foot ulcer among control group was best predicted by subjects' BMI accounting for $46.0 \%$ of the risk for its development, indicating the greet association between obesity and level of risk for developing foot ulcer. These finding were in the same line with [6] who sated in their study about "The relationship of body mass index to diabetes mellitus, hypertension and dyslipidemia: comparison of data from two national surveys" that increased BMI was associated with increased prevalence of diabetes mellitus.

Regarding predictor variables of foot status involving the risk for developing foot ulcer among study group. The present study revealed that the risk of developing diabetic foot ulcer (low risk) among study group was best predicted by subjects' BMI, nature of their work, level of knowledge regarding foot care as well as foot care behavior accounting for $100.0 \%$ of the risk for its development, indicating the highly significant relation between the improved foot care behavior and the lowered risk of developing foot ulcer, also Knowledge on the correct foot care can delay the onset of alterations that lead to ulcers and amputations. These finding were congruent with [33] who found in their study about "Prevalence and Risk Factor of Diabetic Foot Ulcers in a Regional Hospital", that predictors for diabetic foot ulcer (DFU) risk factors included age (OR: $1.04 ; 95 \%$ CI: 1.005-1.074) and daily foot inspection (OR: 0.36 ; 95\% CI: 0.186-0.703). Meanwhile, the predictors for presence of DFU were insulin (OR: 9.37; 95\% CI: 2.240-39.182), shoes (OR: 0.05; 95\% CI: $0.007-0.294)$. Also, [21] concluded from their study about "The efficacy of a diabetic educational program and predictors of compliance of patients with noninsulin-dependent (type 2) diabetes mellitus", that the multinomial regression analysis indicated that marital status, age groups, and daily examination of the feet had a significant effect on the score of HbAlc. [34] who found in their study about "Incidence and Risk Factors of Diabetic Foot Ulcer: A Population-Based Diabetic Foot Cohort (ADFC Study) - Two-Year Follow-Up Study" that the risk factors that were in the model. Finally, history of previous DFU or amputation, insulin usage, gender, distal neuropathy, and foot deformity had a statistically significant relationship with DFU incidence. Patient training on feet did not have any significant correlation with DFU incidence, but it was borderline significant $[\mathrm{OR}=6.66,95 \% \mathrm{CI}(0.75,59.19), \mathrm{P}$ value $=0.089]$.

\section{Conclusion}

Based upon the results of this study, it could conclude that, patients' knowledge about foot care post program was significantly higher among intervention group compared to control group, besides a significantly higher mean scores of self-efficacy, and foot care behavior after program implementation, which in return led to a highly significantly lowered risk of developing foot ulcer among intervention group than in control group, approving the effectiveness of self-care educational program.

\section{Recommendations}

This study recommended that:

Periodic supervision should be provided for patients with diabetes who are at risk for the development of diabetic foot ulcers and should receive ongoing foot-specific patient education to prevent occurrence of complications and improve patients' knowledge, practice, and self-care practices about diabetic foot care.

Regular continuing self-care programs should be designed to enhance patients' skills ability to care for their foot with emphasis on the most important risk factors and appropriate management.

A diabetic educator should be present in each diabetes outpatient clinic and in medical departments.

\section{Future Researches}

Further studies should follow the long-term effect of diabetic foot prevention program to reflect sustained change in the reduction of risk attitudes. Also further study is needed to determine effective factors on the behavior changes among patients with diabetes as a basis for developing preventive nursing intervention in order to improve the foot care.

\section{Acknowledgements}

The authors would like to announce their gratitudefor patients with diabetes involved in the study and extend their deep thanks to all health personnel in the diabetes unit and out patients' clinics at Benha University Hospital for their cooperation in the fulfillment of this study.

\section{References}

[1] Abdelsalam, N., Bakry, H., Said, R., Hammad, M., Mohamed, A. and El Shabrawy, A. (2017): Effectiveness of Health Education Intervention on Foot Self-Care Practice among Diabetics at Zagazig University Hospitals. The Egyptian Journal of Community Medicine, 35 (4): 57-69.

[2] Al-Aboudi, S., Hassali, A. and Shafie, A. (2016): Knowledge, Attitudes, and Quality of Life of Type 2 Diabetes Patients in Riyadh, Saudi Arabia. J Pharm Bioallied Sci, 8 (3): 195-202. doi: 10.4103/0975-7406.171683.

[3] Al-Ghazaly G., Al-Ahwal, L. and Zagloul, K. (2015): Risk Factors of Diabetic Foot Ulcer in Patients Attending Diabetic Foot Outpatient Clinic at Tanta University Hospital in Egypt. The Journal of Diabetic Foot Complications, 7 (2): 42-48.

[4] American Diabetes Association (2015): The Standards of Medical Care in Diabetes. Diabetes Care; 38 (Suppl. 1): S1-S2. 2.

[5] Armstrong D. G., Boulton A. J. M., Bus S. (2017): Diabetic Foot Ulcers and Their Recurrence. The New England Journal of Medicine; 376 (24): 2367-2375. doi: 10.1056/ NEJMra 161 5439 . 
[6] Bays, H.; Chapman, R.; and Grandy, S. (2007): The Relationship of Body Mass Index to Diabetes Mellitus, Hypertension and Dyslipidaemia: Comparison of Data from Two National Surveys. Int J Clin Pract. 2007 May 1; 61 (5): 737-747. doi: $10.1111 / \mathrm{j} .1742-1241.2007 .01336 . x$

[7] Benha University Hospitals Statistical Office, (2017): statistical office Benha university Hospital Elkallubea, Egypt.

[8] Bijoy, C., Feba, B., Vikas, R., Dhandapani, C., Geetha, K. and Vijayakumar, A. (2012): Knowledge Assessment and Patient Counseling on Diabetic Foot Care. Indian Journal of Pharmacy Practice, 5 (2): 11-15. Inlow S. A 60 second foot exam for people with diabetes. Wound Care Canada. 2004; 2 (2): 10-11. (C) CAWC 2011 101E.

[9] Boulton, A Shaw, J (2016): The Pathogenesis Of Diabetic Foot Problems, An Overview, American diabetes Association, pub Med65 (9).

[10] Chin, Y. F., \& Huang, T. T. (2013). Development and Validation of a Diabetes Foot Self-Care Behavior Scale. The Journal of Nursing Research, 21 (1), 19-25.

[11] Dorresteijn, J. A., Kriegsman, D. M, Assendelft, W. J. and Valk, G. D. (2014): Patient Education for Preventing Diabetic Foot Ulceration. Cochrane Database of Systematic Reviews, Issue 12. Art. No.: CD001488. DOI: 10.1002/14651858. CD001488.pub5.www.cochranelibrary.comPatient education for preventing diabetic foot ulceration (Review) Copyright $\mathbb{C}$ 2014 The Cochrane Collaboration. Published by John Wiley \& Sons, Ltd.

[12] El-Sedawy, D. and Behairy, A. (2016): Impact of Preventive Diabetic Foot Nursing Intervention on Foot Status among Patients with Diabetes. Journal of Health, Medicine and Nursing, 25 (1): 104-114. ISSN 2422-8419.

[13] Fan, L., Sidani, S., Cooper-Brathwaite, A. and Metcalfe, K. (2014): Effects of a Foot Self-Care Educational Intervention on Improving Footwear Choices in Those with Type 2 Diabetes at Low Risk of Foot Ulceration. Diabetic Foot Canada Vol 2 No 2 2014.

[14] Friedman, L. M., Furberg, C. D. and DeMets, D. L. (2010): Fundamentals of Clinical Trials: (Chapter 6) Randomization Process, ( $1^{\text {st }}$ ed.). Springer Science+ Business Media: NY. pp. 100-101.

[15] Fujiwara, Y., Kishida, K.., Terao, M., Takahara, M., Matsuhisa, M., Funahashi, T., Shimizu, Y. and Shimomura, I. (2011): Beneficial Effects of Foot Care Nursing for People with Diabetes Mellitus: An Uncontrolled before and after Intervention Study. Journal of Advanced Nursing 67 (9), 1952 1962.

[16] Grillo, M., Neumann, C., Scain, S., Rozeno, R., Beloli, L., Perinetto, T., Gross, J. and LeitãZ, C. (2016): Diabetes Education in Primary Care: A Randomized Clinical Trial. Cad. $\begin{array}{lllll}\text { SaúdePública } & 32 & \text { (5) } 31 & 31 & \text { May2016 }\end{array}$ https://doi.org/10.1590/0102-311X00097115.

[17] Hindi, N., Chabuck, Z., Hindi, S. (2014): A review on role of Nurses in Diabetic Foot Ulcer Prevention and care. European Journal of Nursing. 2014; 1 (1): 22-26.

[18] Inlow'S, A. (2004): 60 second foot exam for people with diabetes. Wound Care Canada.; 2 (2): 10-11.

[19] International Diabetes Federation IDF. (2019): IDF Diabetes
Atlas 8th edition 2017 global fact sheet. https://www.idf.org/aboutdiabetes/what-is-diabetes/facts-figur es.Html.

[20] Lavery, L. A., Peters, E. J., Williams, J. R., Murdoch, J. R., Hudson, A. and Lavery, D. C. (2008): Reevaluating the Way We Classify the Diabetic Foot. Restructuring the Diabetic Foot Risk Classifiation System of the International Working Group on the Diabetic Foot. Diabetes Care 31: 154-156.

[21] Mokabel, F., Aboulazm, S., Hassan, H., Al-Qahtani, M., Alrashedi, S. and Zainuddin, F. (2017): The efficacy of a Diabetic Educational Program and Predictors of Compliance of Patients with Noninsulin-Dependent (type 2) Diabetes Mellitus in Al-Khobar, Saudi Arabia. J Family Community Med, 24 (3): 164-172. doi: 10.4103/jfcm.JFCM_45_16.

[22] Moussa, M. and Gida, N. (2017): Effect of Foot Self-care Program among Diabetic Elderly Adults in Geriatrics Home. IOSR Journal of Nursing and Health Science (IOSR-JNHS). Volume 6, Issue 3 Ver. V (May - June 2017), PP 41-51.

[23] Raghav, A., Khan, Z., Labala, R., Ahmad, J., Noor, S. and Mishra, B. (2018): Financial burden of diabetic foot ulcers to world: a progressive topic to discuss always. TherAdvEndocrinolMetab. 9 (1): 29-31. doi: $10.1177 / 2042018817744513$.

[24] Saleh, N., Shebl, A., Hatata E. and Refiei, M. (2012): Impact of Educational Program about Foot Care on Knowledge and Self-care Practice for Diabetic Older Adult. Journal of American Science; $8 \quad$ (12). Available at http://www.jofamericanscience.org.

[25] Seyyedrasooli, A., Parvan, K., Valizadeh, L., Rahmani, A., Zare, M. and Izadi, T. (2015): Self-Efficacy in Foot Care and Effect of Training: A Single-Blinded Randomized Controlled Clinical Trial. Int J Community Based Nurs Midwifery, 3 (2): 141-9.

[26] Sharoni, S., Abdul Rahman, H., Minhat, H., Ghazali, S. and Ong, M. (2016): A self-Efficacy Education Programme on Foot Self-Care Behavior Among Older patients With Diabetes in A Public Long Term Care Institution, Malaysia: a Quasi experimental Pilot Study. BMJ Open 2017; 7: e014393. doi: 10.1136/bmjopen-2016-014393.

[27] Sharoni, A., Abdul Rahman, H., Minhat, H., Shariff-Ghazali, S. and Ong, A. (2018): The Effects of Self-Efficacy Enhancing Program on Foot Self-Care Behaviour of Older Adults with Diabetes: A Randomised Controlled Trial in Elderly Care Facility, Peninsular Malaysia. PLoS ONE 13 (3): e0192417. https://doi.org/10.1371/journal.pone.0192417

[28] Shaw, P. A., Johnson, L. L. and Borkowf, C. B. (2012): Principles and Practice of Clinical Research: (Chapter 20) Issues in Randomization, (3rd ed.). Ed (s). Gallin, J. I., \& Ognibene, F. P. Elseveir Co.: USA, p. 246.

[29] Sloan, H. L. (2002) Developing and testing of the foot care confidence scale. J Nurs Meas 10: 207-218.

[30] Turns, M. (2013): "Diabetic foot ulcer management: the podiatrist's perspective". Br J Community Nurs. Suppl: S14, S16-9.

[31] World Health Organization (WHO). (2019): Diabetes Programme. Available @ https://www.who.int/diabetes/action online/basics/en/index3.h tml. Accessed in 5 February, 2019. At 8:00 pm. 
[32] Yamane, T. (1967): Statistics an Introductory Analysis. 2nd Ed. New York Harper and Row CO. USA, 213.

[33] Yusuf, S., Okuwa, M., Irwan, M., Rassa, S., Laitung, B., Thalib, A., Kasim, S., Sanada, H., Nakatani, T. and Sugama, J. (2016): Prevalence and Risk Factor of Diabetic Foot Ulcers in a Regional Hospital, EasternIndonesia. Open Journal of Nursing, 2016, 6, 1-10 Published Online January 2016 in Sci Res. http://www.scirp.org/journal/ojn.

http://dx.doi.org/10.4236/ojn.2016.61001.
[34] Yazdanpanah, L., Shahbazian, H., Nazari, I., Arti, H., Ahmadi, F., Mohammadianinejad, S. Cheraghian, B. and Hesam, S. (2018): Incidence and Risk Factors of Diabetic Foot Ulcer: A Population-Based Diabetic Foot Cohort (ADFC Study) - Two-Year Follow-Up Study. Int J Endocrinol. 2018; 7631659. Published online 2018 Mar 15. doi: $10.1155 / 2018 / 7631659$. 